OPEN ACCESS

Edited by:

F. L. Consoli,

University of São Paulo, Brazil

Reviewed by:

Xianhua Liu,

Tianjin University, China

Beatriz Sabater-Munoz,

Polytechnic University of Valencia,

Spain

${ }^{*}$ Correspondence: Manuel Aranda

manuel.aranda@kaust.edu.sa

Specialty section:

This article was submitted to

Microbial Symbioses,

a section of the journal

Frontiers in Microbiology

Received: 10 May 2021 Accepted: 28 October 2021 Published: 25 November 2021

Citation:

Barreto MM, Ziegler M, Venn A, Tambutté E, Zoccola D, Tambutté S, Allemand $D$, Antony $C P$, Voolstra $C R$

and Aranda M (2021) Effects of Ocean Acidification on Resident and Active Microbial Communities

of Stylophora pistillata.

Front. Microbiol. 12:707674. doi: 10.3389/fmicb.2021.707674

\section{Effects of Ocean Acidification on Resident and Active Microbial Communities of Stylophora pistillata}

\author{
Marcelle Muniz Barreto ${ }^{1}$, Maren Ziegler ${ }^{2}$, Alexander Venn ${ }^{3}$, Eric Tambutté ${ }^{3}$, \\ Didier Zoccola ${ }^{3}$, Sylvie Tambutté ${ }^{3}$, Denis Allemand ${ }^{3}$, Chakkiath Paul Antony ${ }^{1}$, \\ Christian R. Voolstra ${ }^{1,4}$ and Manuel Aranda ${ }^{1 *}$
}

${ }^{1}$ Red Sea Research Center, Division of Biological and Environmental Science and Engineering (BESE), King Abdullah University of Science and Technology, Thuwal, Saudi Arabia, ${ }^{2}$ Department of Animal Ecology and Systematics, Justus Liebig University Giessen, Giessen, Germany, ${ }^{3}$ Center Scientifique de Monaco, Monaco, Monaco, ${ }^{4}$ Department of Biology,

University of Konstanz, Konstanz, Germany

Ocean warming and ocean acidification $(\mathrm{OA})$ are direct consequences of climate change and affect coral reefs worldwide. While the effect of ocean warming manifests itself in increased frequency and severity of coral bleaching, the effects of ocean acidification on corals are less clear. In particular, long-term effects of OA on the bacterial communities associated with corals are largely unknown. In this study, we investigated the effects of ocean acidification on the resident and active microbiome of long-term aquaria-maintained Stylophora pistillata colonies by assessing 16S rRNA gene diversity on the DNA (resident community) and RNA level (active community). Coral colony fragments of $S$. pistillata were kept in aquaria for 2 years at four different $\mathrm{pCO}_{2}$ levels ranging from current $\mathrm{pH}$ conditions to increased acidification scenarios (i.e., $\mathrm{pH} 7.2,7.4,7.8$, and 8). We identified 154 bacterial families encompassing 2,047 taxa (OTUs) in the resident and 89 bacterial families including 1,659 OTUs in the active communities. Resident communities were dominated by members of Alteromonadaceae, Flavobacteriaceae, and Colwelliaceae, while active communities were dominated by families Cyclobacteriacea and Amoebophilaceae. Besides the overall differences between resident and active community composition, significant differences were seen between the control $(\mathrm{pH}$ 8) and the two lower $\mathrm{pH}$ treatments (7.2 and 7.4) in the active community, but only between $\mathrm{pH} 8$ and 7.2 in the resident community. Our analyses revealed profound differences between the resident and active microbial communities, and we found that OA exerted stronger effects on the active community. Further, our results suggest that rDNA- and rRNA-based sequencing should be considered complementary tools to investigate the effects of environmental change on microbial assemblage structure and activity.

Keywords: climate change, coral microbiome, 16S rDNA, 16S rRNA, coral holobiont

\section{INTRODUCTION}

Coral reefs are among the most biodiverse and productive ecosystems in the world. Despite covering less than $0.2 \%$ of the marine environment, they harbor $34 \%$ of the described marine biodiversity (Reaka-Kudla, 2001). Hundreds of millions of people depend on them for their livelihood, since they provide goods and services such as fisheries, tourism, coastal protection, 
pharmaceutical substances and aesthetic and cultural value (Moberg and Folke, 1999). The framework of reefs is built by scleractinian corals. They are referred to as holobionts, obligate symbiotic organisms that live in close association with microorganisms such as endosymbiotic photosynthetic algae, bacteria, archaea, viruses and fungi (Rohwer et al., 2002; Rosenberg et al., 2007). Many studies have looked into the symbiotic relationship with the dinoflagellate algae from the family Symbiodiniaceae (LaJeunesse et al., 2018), but less is known about the bacterial partners in this association. The coral microbiome has a range of functional roles, including nitrogen fixation (Lesser et al., 2004; Lema et al., 2012; Pogoreutz et al., 2017a,b), sulfur cycling (Raina et al., 2009), antibacterial activities (Ritchie, 2006) and overall holobiont health (Rosenberg et al., 2007; Robbins et al., 2019; Voolstra and Ziegler, 2020). As high throughput sequencing of microbial DNA becomes more accessible, studies based on analysis of phylogenetic markers such as the 16S rRNA gene become increasingly available.

Coral reefs are declining globally, mainly due to rising $\mathrm{CO}_{2}$ emissions (Hoegh-Guldberg, 2007; Hughes et al., 2017). Besides causing ocean warming, rising $\mathrm{CO}_{2}$ in the atmosphere is also linked to ocean acidification (OA), which is caused by elevated partial pressure of carbon dioxide $\left(p \mathrm{CO}_{2}\right)$ in the seawater that alters carbonate ion chemistry and reduces seawater $\mathrm{pH}$ (Doney et al., 2009). Seawater surface $\mathrm{pH}$ has decreased 0.1 units since pre-industrial values and is predicted to decrease another $0.2-$ 0.4 units by 2100 (Rhein, 2014). There is evidence that OA can negatively impact calcifying organisms, such as scleractinian corals, by decreasing their calcification rate and photosynthesis (Anthony et al., 2008; Doney et al., 2009). However, it is still not clear how OA might affect the coral microbiome, and consequently holobiont physiology and health. Some studies showed that OA can shift coral microbiome composition from a healthy-associated community to one usually seen in diseased and stressed corals (Thurber et al., 2009; Meron et al., 2011; Webster et al., 2013), while others show a stable microbiome (Meron et al., 2012; Webster et al., 2016) or species-specific responses (Morrow et al., 2015; Grottoli et al., 2018).

Most studies that characterized microbial community composition were based on $16 \mathrm{~S}$ rDNA amplicon sequencing, an established method that can successfully describe microorganisms present in the community (Lane et al., 1985; Weisburg et al., 1991). However, one limitation of this method is that it includes any DNA, including DNA from dormant and dead microbes, making it impossible to distinguish the metabolically active from the non-active population (Pietramellara et al., 2009; Blagodatskaya and Kuzyakov, 2013; Carini et al., 2016). Alternatively, sequencing 16S rRNA serves as an effective proxy to estimate active microbial populations, since it is a component of ribosomes, which are predicted to increase in number with increasing metabolic activity (Poulsen et al., 1993). In addition, once outside the cell, RNA degrades faster than DNA, ensuring sampling of only the active community. Thus, the ratio of rRNA/rDNA of a specific taxon can be used as a measure of its potential activity (Jones and Lennon, 2010), although this approach is not without its caveats (Blazewicz et al., 2013). Many studies have pointed out a mismatch between the DNA/RNA based communities (DeAngelis and Firestone, 2012; Dlott et al., 2015; Steven et al., 2017). Hence, simultaneous sequencing and comparison of both components can unveil rare but highly active, as well as abundant and inactive taxa (Jones and Lennon, 2010; Campbell et al., 2011; Gaidos et al., 2011; Lanzén et al., 2011; Hunt et al., 2013).

In this study, we assessed the effect of long term increased $p \mathrm{CO}_{2}$ treatments on the microbial community of the Red Sea coral Stylophora pistillata at both the 16S rDNA and rRNA level to obtain an integrative view of the effects on the resident and active microbial partners.

\section{MATERIALS AND METHODS}

\section{Coral Husbandry}

Nubbins of Stylophora pistillata have been kept in a long-term experimental aquarium setup since the early 2010's at the Monaco Scientific Centre as described previously (Venn et al., 2013; Tambutté et al., 2015; Liew et al., 2018) and were sampled for this study in April 2014, after 2 years of OA treatment. Coral nubbins were exposed to four different $p \mathrm{CO}_{2}$ treatments: $2,447.48 \pm 7.16$, $2,461.77 \pm 5.97,2,474.16 \pm 5.89$ and 2,496.62 $\pm 6.99 \mu \mathrm{mol}$ $\mathrm{kg}^{-1}$ total alkalinity. These treatments were equivalent to: $\mathrm{pH}$ 8.0 (control), 7.8, 7.4 and 7.2, respectively. Colonies were divided into four fragments and placed under the different treatments, with three fragments sampled from each treatment. Carbonate chemistry was manipulated by bubbling $\mathrm{CO}_{2}$ to decrease $\mathrm{pH}$ to the desired target values $\left(\mathrm{COO}_{2}\right.$ levels: $537.66 \pm 4.88$, $798.77 \pm 14.36,2109.3 \pm 59.63,3513.15 \pm 67.20 \mu \mathrm{atm})$. Temperature and $\mathrm{pH}$ were monitored in the four treatment tanks with probes (Ponsel-Mesure, France) linked to a monitoring system (Enoleo, Monaco) that also controlled $\mathrm{CO}_{2}$ bubbling. Mediterranean water was supplied at an exchange rate of $70 \%$ $\mathrm{h}^{-1}$, adjusted to $38 \mathrm{~g} \mathrm{liter}^{-1}$ salinity and $25^{\circ} \mathrm{C}$ temperature. Light intensity was set to $170 \mu \mathrm{mol}$ photons $\mathrm{m}^{-2} \mathrm{~s}^{-1}$ with a $12 \mathrm{~h}$ light/12 h dark photoperiod with HQI10000K metal halide lamps (BLV Nepturion). Total alkalinity (TA) and $\mathrm{pH}$ were measured daily, and carbonate seawater chemistry was calculated as described previously (Tambutté et al., 2015).

\section{DNA and RNA Extraction, Reverse Transcription, and $16 S$ rRNA Gene and Transcript Amplicon Sequencing}

Stylophora pistillata DNA was extracted with DNeasy PowerBiofilm (Qiagen, Hilden, Germany) following manufacturer's instructions. Briefly, small pieces from nubbins of $S$. pistillata were collected in PowerBiofilm Bead tubes and homogenized with CryoMill (Retsch, Germany). Triplicates were extracted for each $\mathrm{pH}$ condition. Following centrifugation, supernatants were passed through Silica Spin Filter Tubes and after washing steps, DNA was eluted in $10 \mathrm{mM}$ Tris.

Total RNA was isolated from triplicates collected for each $\mathrm{pH}$ treatments using RNeasy kit (Qiagen) according to manufacturer's instructions. First-strand cDNA was synthesized 
using a SuperScript III First Strand Synthesis SuperMix Kit (Invitrogen). Reactions were done using a mixture of annealing buffer and random hexamers, with $20 \mu \mathrm{l}$ total volume. Thermo cycler conditions were as follows: $50 \mathrm{~min}$ at $50^{\circ} \mathrm{C}, 7 \mathrm{~min}$ at $25^{\circ} \mathrm{C}$, $50 \mathrm{~min}$ at $50^{\circ} \mathrm{C}$ and $5 \mathrm{~min}$ at $85^{\circ} \mathrm{C}$.

For $16 \mathrm{~S}$ rRNA amplicon sequencing, triplicate PCR reactions of $25 \mu \mathrm{l}$ final volume were done using the Qiagen Multiplex PCR kit using $30 \mathrm{ng} / \mu \mathrm{l}$ of template DNA and cDNA. For amplification we targeted variable regions 5 and 6 of the $16 \mathrm{~S}$ rRNA gene using primers $784 \mathrm{~F}$ (5'TCGTCGGCAGCGTCAGATGTGTATAAGAGACAGAGGA TTAGATACCCTGGTA'3) and 1061R (5' 'GTCTCGTGGGC $^{\prime}$ TCGGAGATGTGTATAAGAGACAG-CRRCACGAGCTGACG $\mathrm{AC}^{\prime} 3$ ) (Andersson et al., 2008; Bayer et al., 2013) with Illumina adapter overhangs (underlined). Final primer concentration was of $0.5 \mu \mathrm{M}$. PCR conditions consisted of initial denaturing step at $95^{\circ} \mathrm{C}$ for $15 \mathrm{~min}$, followed by 27 cycles of $95^{\circ} \mathrm{C}$ for $30 \mathrm{~s}, 55^{\circ} \mathrm{C}$ for $90 \mathrm{~s}$, and $72^{\circ} \mathrm{C}$ for $30 \mathrm{~s}$, and a final extension step at $72^{\circ} \mathrm{C}$ for $10 \mathrm{~min}$. To confirm amplification from the right size, we ran $1 \%$ agarose gel using $4 \mu \mathrm{l}$ PCR product.

\section{Library Preparation and Sequencing}

Triplicate PCRs for each sample were pooled, and cleaned using the Mini Elute PCR purification kit (Qiagen, Hilden, Germany), following manufacturer instructions. PCR products were indexed with Nextera XT barcoded sequencing adapters (Illumina, San Diego, CA, United States) and cleaned again following manufacturer instructions. Indexed PCR products were then quantified with QuBit (dsDNA High Sensitivity Assay Kit, Thermo Fisher Scientific, Waltham, MA, United States) and pooled in equimolar ratios. Pooled samples were inspected for quality on the BioAnalyzer (Agilent Technologies, Santa Clara, CA, United States) and sequenced at $6 \mathrm{pM}$ on the Illumina MiSeq, 2 bp $\times 300$ bp paired-end v3 chemistry according to the manufacturer instructions.

\section{Sequence Data Processing and Analysis}

Raw reads were quality-filtered $(\mathrm{QV}=25)$ and decontaminated of Illumina adapter and phiX sequences using the BBDuk tool from the BBMap v37.62 suite (Bushnell $\mathrm{B}^{1}$ ). Mothur v1.44.3 (Schloss et al., 2009) was used for sequence data processing and analysis. Briefly, forward and reverse reads were assembled into contigs and ambiguous reads removed before quality trimming and pre-clustering took place (Huse et al., 2010). After exclusion of singletons, sequences were aligned to the Silva database 138.1 (Pruesse et al., 2007). Chimeric sequences were further excluded with UCHIME (Edgar et al., 2011), as were chloroplast, mitochondrial, archaeal, and eukaryotic sequences using the remove.lineages command in mothur. Sequences were then classified against the Silva database (McDonald et al., 2012). Sequences were reclassified against the Silva database after subsampling to 10,669 sequences, which was the highest number of sequences possible while still keeping all replicates. Operational Taxonomic Units (OTUs) were defined based on

${ }^{1}$ http://sourceforge.net/projects/bbmap/ sequence clustering at a $97 \%$ similarity cutoff and used for following analysis.

We used $\mathrm{R}$ (version 3.5.1, 2018) and PRIMER E v6 (PERMANOVA+) software for multivariate analysis on Log $(\mathrm{x}+1)$ transformed OTU count data (Clarke and Gorley, 2006). Difference between groups according to genetic material (i.e., DNA vs. RNA) and $\mathrm{pH}$ treatment were visualized with non-metric MultiDimensional Scaling (nMDS) plots, based on Bray-Curtis dissimilarity distances. One-factorial PERmutational MANOVAs (PERMANOVAs) were used to test for differences between DNA vs. RNA material and $\mathrm{pH}$ treatments. We also performed an analysis of similarity percentages (SIMPER; Clarke, 1993) based on Bray Curtis resemblance matrix to identify OTUs mainly responsible for dissimilarity between groups. Alpha diversity indices (Chao1, Inverse Simpson, Simpson Evenness) were calculated for each sample in mothur. Samples were tested for normality and homoscedasticity with Shapiro-Wilk and Levene's test, before being analyzed for differences between $\mathrm{pH}$ treatments using ANOVA with Tukey post hoc tests in $\mathrm{R}$ (version 3.5.1, 2018). The putative core microbiome of S. pistillata was defined by identifying bacterial OTUs present in all treatment and replicates.

Significantly differences in OTU abundance amongst treatments were analyzed by the linear discriminant analysis (LDA) effect size (LEfSe) method (Segata et al., 2011) on the website https://huttenhower.sph.harvard.edu/galaxy/root $(\mathrm{LDA}>2)$.

\section{RESULTS}

\section{Sample and Sequencing Overview}

Illumina MiSeq sequencing of bacterial $16 \mathrm{~S}$ rDNA and rRNA amplicons generated a total of 4,157,907 sequences from 24 samples [average $173,247 \pm 100,095$ (SD)], being 1,482,981 for RNA samples and 2,674,938 for DNA samples (Supplementary Table 1). After quality filtering and exclusion of chimeras and unwanted sequences, 1,474,649 remained, with an average of $61,444 \pm 38,313$ (SD). From these, 14,829 distinct sequences were identified after clustering at 97\% similarity and assigned to bacteria. Subsampling was done to 10,669 sequences, which was the highest number that allowed keeping all replicates. After quality filtering, DNA samples contained an average of 76,488 sequences (range from 13,735 to 165,630 ), while RNA samples contained an average of 46,399 sequences (range from 10,669 to 114,558 , Supplementary Table 1). Rarefaction curves for DNA and RNA samples suggested that subsampling to 10,669 was indeed sufficient to capture most of bacterial diversity (Supplementary Figure 1A).

\section{Distinct Bacterial Communities Based on 16S rDNA and 16S rRNA Sequencing}

We identified a total of 154 bacterial families for DNA- and 89 bacterial families for RNA-based sequencing. DNA samples were dominated by members of Alteromonadaceae (24.52\%), Flavobacteriaceae $(24.17 \%)$ and Colwelliaceae (18.51\%), while RNA samples were dominated by families Cyclobacteriacea and 

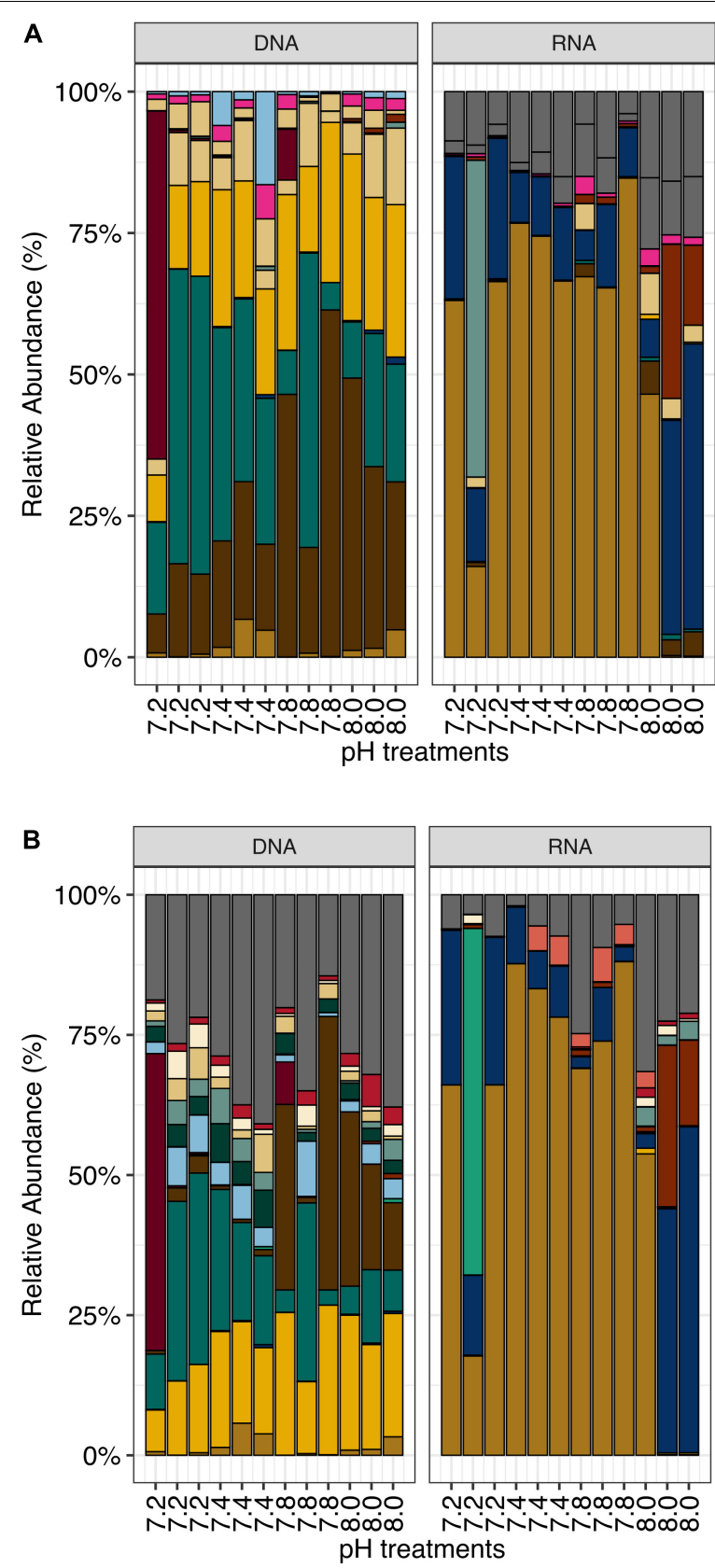

\section{Family}

Other $<1 \%$

Pseudoalteromonadaceae

Bacteria unclassified

Saccharospirillaceae

Alcaligenaceae

Cellvibrionaceae

Chlorobiaceae

Rhodobacteraceae

Colwelliaceae

Amoebophilaceae

Alteromonadaceae

Flavobacteriaceae

Cyclobacteriaceae
OTU

Other $<1 \%$

Candidatus_Amoebophilus

Thalassobius sp.

Shimia $\mathrm{sp}$.

Thalassolituus sp.

Kordia sp.

Tenacibaculum sp.

Castellaniella sp.

Alteromonas sp2

Unclassified Prosthecochloris

Unclassified Cellvibrionaceae

Unclassified Flavobacteriaceae

Alteromonas sp1

Candidatus Amoebophilus

Thalassotalea sp.

Fulvivirga sp.

FIGURE 1 | (A) Most abundant bacterial families (>1\%) and (B) OTUs in samples from Stylophora pistillata kept in aquaria for 2 years at different pH treatments (pH $7.2,7.4,7.8$ and 8.0 ), after subsampling to 10,669 reads.

Amoebophilaceae (57.97 and 20.69\%, respectively, Figure 1A). For further analyses, sequences were clustered into Operational Taxonomic Units (OTUs) at a 97\% similarity level. A total of 3,266 OTUs were identified from this dataset. DNA samples contained 2,047 OTUs, while RNA samples contained 1,659 OTUs. DNA samples were dominated by Thalassotalea sp. (18.37\% relative abundance, OTU0002, $100 \%$ identical to Thalassotalea sp. GenBank accession no. MN822801.1), Alteromonas sp. (16.54\% relative abundance, OTU0003, 100\% identical to Alteromonas macleodii, GenBank accession no.
CP018321.1) and unclassified Flavobacteriaceae (12.77\% relative abundance, OTU0005, 98.95\% identical to Polaribacter sp., GenBank accession no. MK818916.1, Figure 1B). In contrast, Fulvivirga sp. (OTU0001, 95.85\% identical to Fulvivirga sp., GenBank accession no. JQ516517.1) dominated RNA samples (57.00\% relative abundance), followed by Candidatus amoebophilus, (OTU0004, 17.69\%, Figure 1B).

In each $\mathrm{pH}$ treatments, some OTUs were present exclusively in RNA samples while others were exclusively found in DNA samples (Supplementary Figures 1B-E). Yet, most of the top 
abundant OTUs were present in both DNA and RNA samples, (Supplementary Table 2) despite a noticeable disparity in abundance. For instance, the most abundant bacterial OTU found in DNA, Thalassotalea sp., (OTU0002), only accounted for $0.18 \%$ in RNA samples. Similarly, Fulvivirga sp. (OTU0001) accounted for more than half of the bacterial community in RNA samples, yet, they only represented $1.47 \%$ of the relative abundance in DNA samples. The next three most abundant taxa found in DNA samples accounted for only between 0.007 and $0.04 \%$ of the relative abundance in RNA samples. Similarly, following the same pattern, the next three most abundant taxa in RNA samples accounted for only between 0.15 and $0.17 \%$ of the relative abundance in DNA samples (Supplementary Figure 2A). In fact, Stylophora pistillata's bacterial community was distinct when comparing 16S rDNA and 16S rRNA sequencing results from the same samples (PERMANOVA, pMC $=0.0001$, Figure 2A). Furthermore, Simper analysis indicated a dissimilarity value between DNA and RNA samples of $87.14 \%$ (Supplementary Table 3). Alteromonas sp. (OTU0004), Thalassotalea sp. (OTU0002) and Tenacibaculum sp. (OTU0010) contributed the most to the DNARNA dissimilarity (Supplementary Table 4).

\section{Decreased pH Has Larger Impact on Active Bacterial Communities}

We identified approximately even numbers of OTUs in DNA samples with a total of 730 OTUs at $\mathrm{pH} 8.0,717$ at $\mathrm{pH} \mathrm{7.8,}$ 796 at 7.4, and 871 at 7.2 in the DNA samples and 131 OTUs were shared between all pH groups (Supplementary Figure 2B). For RNA samples, the number of OTUs was decreasing with

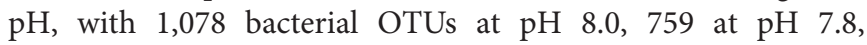
166 at $\mathrm{pH} 7.4$ and 169 at $\mathrm{pH} 7.2$, with only 33 shared OTUs between all $\mathrm{pH}$ groups (Supplementary Figure 2C). When considering only the DNA data, there was a significant general effect of $\mathrm{pH}$ (PERMANOVA, pMC $=0.02$, Pseudo $F=2.0182$ ), with significant differences between $\mathrm{pH} 7.2$ and 8.0 ( $\mathrm{pMC}=0.0312, t=1.9779$, Figure 2B). We observed increased abundance of families Flavobacteriaceae at pH 7.8 and 8.0 (40 and 29\%), and Chlorobiaceae and Alteromonadaceae at $\mathrm{pH} 7.2$ (19 and 37\% respectively, Figure 1A). At OTU level, unclassified Flavobacteriaceae (OTU0005) was relatively more abundant at pH 7.8 and 8.0 (28 and 21\%, respectively), while Alteromonas sp. (OTU0004) and Prostheocochloris sp. (OTU0007) was more abundant at $7.2 \mathrm{pH}$ treatments (25 and 18\%, respectively) (Figure 1B). LEfSe analysis indicated 14 representative OTUs for $\mathrm{pH}$ 8.0, four for $\mathrm{pH} 7.8$, seven for $\mathrm{pH} 7.4$ and seven for $\mathrm{pH} 7.2$ in DNA samples (Figure 3A).

When considering only the RNA data, there was also a significant effect of $\mathrm{pH}$ (PERMANOVA, $\mathrm{pMC}=0.0044$, Pseudo $F=2.8021$, Figure 2C), yet with significant differences between $\mathrm{pH} 7.2$ and $8.0(\mathrm{pMC}=0.0332, t=1.9342)$ and between $\mathrm{pH} 7.4$ and 8.0 ( $\mathrm{pMC}=0.0228, t=2.1838)$. Cellvibrionaceae was more abundant at $\mathrm{pH} 7.2$, while Cyclobacteriaceae decreased in relative abundance at $\mathrm{pH}$ 8.0. Families Alcaliginaceae, Amoebophilaceae, Rhodobacteriaceae and Flavobacteriaceae were more abundant at pH 8.0 (Figure 1A). At OTU level, Castellaniella sp. and
"Candidatus Amoebophilus" were more abundant at $\mathrm{pH}$ 8.0. Fulvivirga sp. was less abundant at $\mathrm{pH}$ 8.0, while unclassified Cellvibrionaceae was more abundant at $\mathrm{pH} 7.2$ (Figure 1B). LEfSe analysis identified five microbial OTUs enriched at $\mathrm{pH}$ 8.0, two at pH 7.8 and one enriched at pH 7.4 (Figure 3B).

Alpha diversity measures (Chao estimate of species richness, Shannon diversity and Simpson evenness indices) were calculated using mothur. While Shannon diversity index was significantly higher in the control treatment $(\mathrm{pH} \mathrm{8.0)}$ compared to 7.2 and $7.4 \mathrm{pH}$ (ANOVA, $p<0.05$; Tukey, $p<0.05$ ) at the RNA level, the same was not observed at the DNA level (Table 1). Although the control treatment showed a pattern of higher Chao estimated richness at RNA level than at low $\mathrm{pH}$, and higher in $\mathrm{pH} 7.2$ at DNA level than at high $\mathrm{pH}$, this was not statistically significant (Kruskal-Wallis, $p>0.05$ ). Community evenness was similar amongst $\mathrm{pH}$ treatments at DNA level (ANOVA, $p<0.05$ ), while a significant decreasing pattern was observed from low to high $\mathrm{pH}$ at RNA level with the least even communities at control $\mathrm{pH}$ (ANOVA, $p<0.05$, Table 1).

\section{Core Microbiome}

Bacterial OTUs that were present in all treatments and all replicates (from DNA samples only) were considered to constitute the putative core microbiome. This resulted in 23 taxa that were consistently found to be part of the microbiome of Stylophora pistillata (Table 2). Amongst them, Thalassotalea sp. (18.37\% of relative abundance), Alteromonas sp. (16.54\%) and unclassified Flavobacteriaceae $(12.77 \%)$ were the most abundant taxa. The remaining taxa showed substantially lower relative abundances, ranging from 4.18 to $0.04 \%$.

\section{DISCUSSION}

\section{Discrepancy Between Resident and Active Bacterial Communities in Response to Ocean Acidification}

This is the first research to assess the effects of OA on a coral microbiome considering both the resident and active bacterial communities. Sequencing of $16 \mathrm{~S}$ rDNA gene is a de facto standard method to identify microbial communities. However, a major disadvantage of this method is that DNA can remain in the environment after cell death, making it challenging to distinguish active from dormant populations or even extracellular material (Carini et al., 2016). Since RNA is short-lived, and ribosome quantity is generally associated with active growth and cellular activity, some authors consider sequencing of reverse transcribed rRNA a more accurate representation of metabolically active microbial communities (Ramos et al., 2000).

In this study, we found differences in bacterial community composition and relative abundance when sequencing the resident (DNA) and active (RNA) communities from the same samples. The top OTUs most contributing to these differences were around 4-8 times more abundant in the resident than the active community. Interestingly, a previous study on marine sediments detected $16 \mathrm{~S}$ rDNA gene abundances of bacterial 

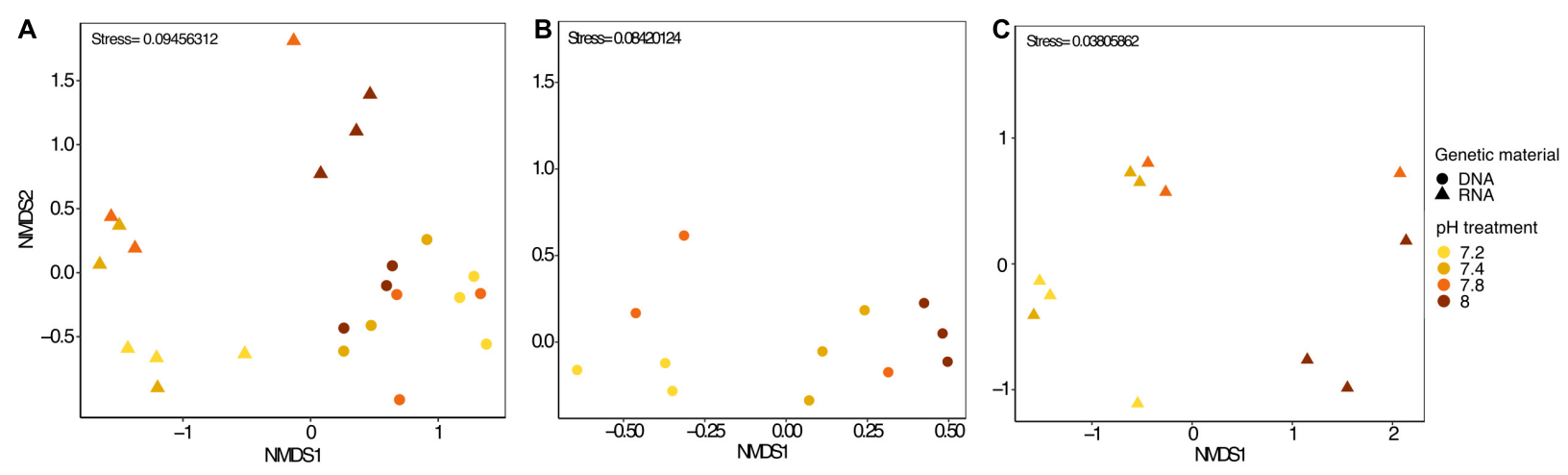

FIGURE 2 | (A) nMDS plot including all microbial samples (DNA and RNA), (B) only microbial DNA samples and (C) only microbial RNA samples from Stylophora pistillata kept in aquaria for 2 years at different $\mathrm{pH}$ treatments $(\mathrm{pH} 7.2,7.4,7.8$ and 8.0). Data was transformed to Log ( $\mathrm{X}+1)$ and resemblance matrix based on Bray Curtis similarity.

communities 1-2 orders of magnitude higher than the transcript abundances ( $\mathrm{Li}$ et al., 2020). Conversely, some OTUs were more abundant in the active community. This decoupling could be explained by either a response to specific treatment or by a substantial fraction of bacteria becoming active when their abundance decreased. This could suggest that high abundance limits activity or that top-down processes, such as grazing and virus lysis, could be involved in promoting or regulating activity (Berdjeb et al., 2011).

Interestingly, we found many OTUs exclusively in either the resident or the active communities, with only $13.5 \%$ overlap between both sources. However, the majority of the most abundant OTUs were present in both fractions. Previous studies found that only $29-50 \%$ of $16 \mathrm{~S}$ rDNA sequences were identical to sequences in the 16S rRNA library from the same soil (Nogales et al., 2001; Mengoni et al., 2005; Lillis et al., 2009). Other studies also detected stark differences between 16S rDNA and rRNA libraries from soil samples (Baldrian et al., 2012; Romanowicz et al., 2016) and the coral L. pertusa (Galand et al., 2018). Undetected OTUs may reflect low abundance below PCR amplification levels (Mengoni et al., 2005) or they could be excluded during subsampling. In a biological context, the presence of a specific taxa in only rDNA samples could indicate lack of activity, while exclusively detecting taxa on the rRNA level might indicate rare species that are highly active. It could also indicate colonization by opportunistic bacteria that are likely not active and have low ecological relevance (Galand et al., 2018).

Our results showed higher OTU richness and diversity for resident compared to active communities, indicating that the metabolically active bacterial components in S. pistillata constitute only a fraction of the total microbiome. A similar pattern was observed by other authors for bacterial populations in the rhizosphere of Chrysanthemum (Duineveld et al., 2001), coral reef and marine sediments (Gaidos et al., 2011), as well as other studies based on sequencing of bacterial communities from different environments (Lanzén et al., 2011; Weigold et al., 2016). The higher richness and diversity of DNA based libraries is likely a reflection of recovering a broader range of microbes, including active, dormant and even dead cells as opposed to only active cells detected by RNA based libraries (Salgar-Chaparro and Machuca, 2019).

However, it is important to note that bias introduced by PCRinduced artifacts and different extraction methods for DNA and RNA, including the use of RNA protection agents, is a recurrent problem when characterizing microbial communities (Acinas et al., 2005; McCarthy et al., 2015).

\section{Ocean Acidification Effects Are Distinct Between Resident and Active Microbial Communities}

Many studies have evaluated the effects of ocean acidification on the coral microbiome, but most of them focused only on sequencing of $16 \mathrm{~S}$ rDNA (O'Brien et al., 2016). While these studies found some effect of OA on community composition and function (Webster et al., 2013, 2016; Morrow et al., 2015; Grottoli et al., 2018), others reported a stable microbiome (Meron et al., 2012; Zhou et al., 2016; O’Brien et al., 2018). In this study, we detected a significant difference in bacterial communities from $\mathrm{pH} 7.2$ and $\mathrm{pH} 8.0$ in both active and resident bacterial communities, and from pH 7.4 and 8.0 in the active community. Overall, we found stronger differences in response to OA in the active compared to the resident bacterial communities. A similar pattern was observed by other authors in response to pollution and toxic compounds (Mengoni et al., 2005; Hoshino and Matsumoto, 2007; Lillis et al., 2009). This pattern is, to some extent, expected since the resident community also encompasses dead and non-active cells that will not respond to changes in the environment. Thus, our data support the notion that RNA better describes the actively responding community, which should show the most direct effects of disturbance (Mengoni et al., 2005).

We observed a drop in richness and diversity in the active community with decreasing $\mathrm{pH}$, suggesting growth and activity limitation at low $\mathrm{pH}$ for many bacterial OTUs. For instance, Castellaniella sp. (OTU 0009, 100\% identical to Castellaniella denitrificans, GenBank accession no. MK039104.1), which is from the Alcaligenaceae family and known to be involved in 

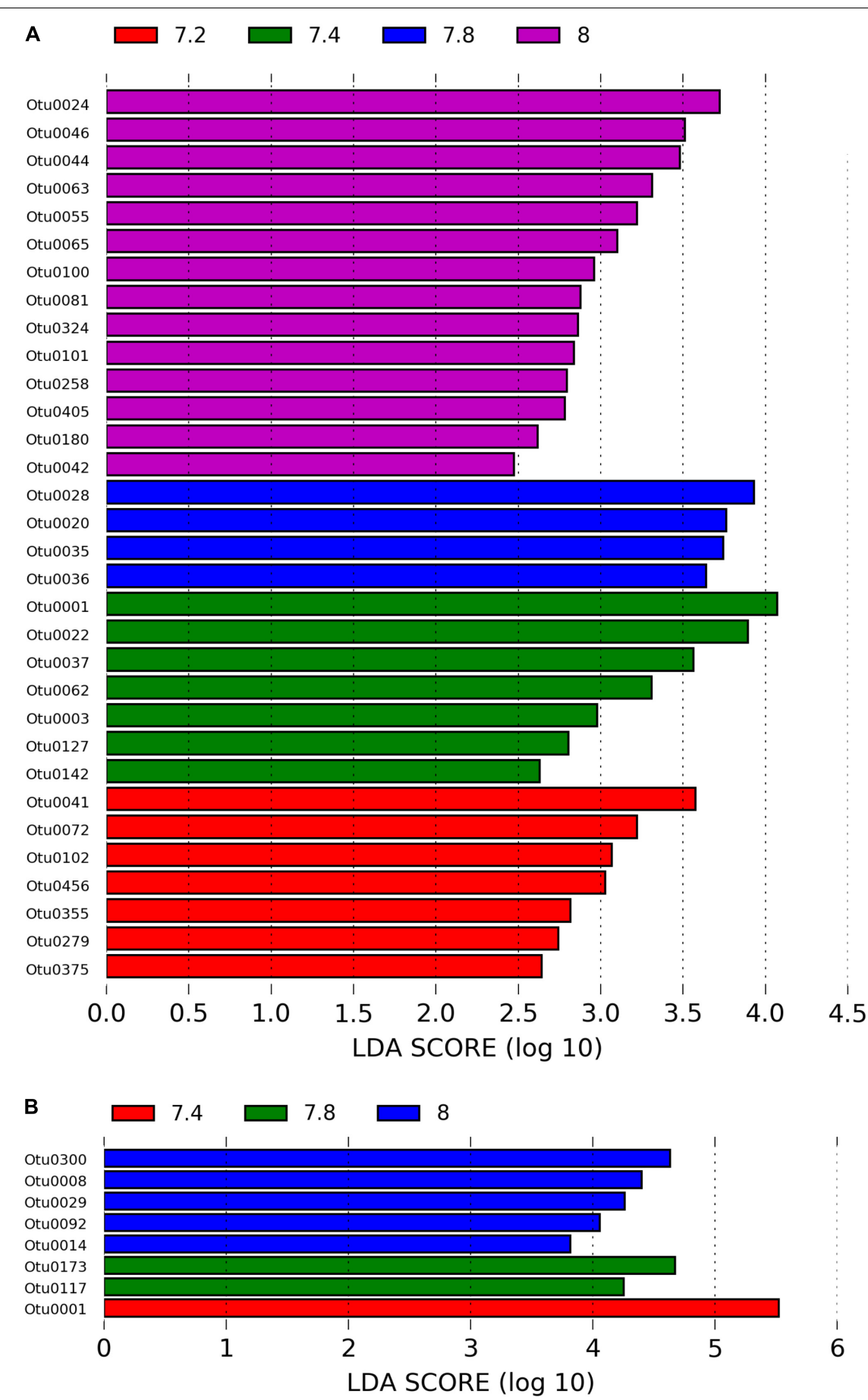

FIGURE 3 | (A) LEfSe analysis identifying representative OTUs from microbial DNA samples and (B) microbial RNA from Stylophora pistillata kept in aquaria for 2 years at different $\mathrm{pH}$ treatments $\left(\mathrm{pH} 7.2,7.4,7.8\right.$ and 8.0), with a cutoff value of LDA score $\left(\log _{10}\right)$ above 2.

denitrification processes (Rosenberg, 2013) was present in the resident community at all $\mathrm{pH}$ levels, but decreased with $\mathrm{pH}$ in the active community. Similarly, studies on denitrifying prokaryotes in soil, wastewater sludges and batch reactor cultures found a decrease in denitrification activity in low $\mathrm{pH}(<6.5)$ (Thörn and Sörensson, 1996; Ellis et al., 1998). Denitrifying prokaryotes are found in coral holobionts worldwide (Gaidos et al., 2011; Yang et al., 2013; Rädecker et al., 2015; Tilstra et al., 2019). Denitrification by members of the coral microbiome may have a potential role in contributing to a balanced nitrogen to phosphorous ratio by decreasing nitrogen levels in coral tissues. Maintaining a N-limited state may generally contribute 
TABLE 1 | Differences in alpha diversity indices (Chao estimate of species richness, Shannon and Simpson evenness) in microbiome of Stylophora pistillata kept in aquaria for 2 years at different $\mathrm{pH}$ treatments $(7.2 ; 7.4,6.8$ and 8.0) for DNA and RNA samples.

\begin{tabular}{|c|c|c|c|c|c|c|c|c|c|c|}
\hline \multicolumn{2}{|c|}{ Treatment } & \multicolumn{3}{|c|}{ Chao1 } & \multicolumn{3}{|c|}{ Shannon } & \multicolumn{3}{|c|}{ Simpson evenness } \\
\hline & & Mean & SD & SE & Mean & SD & SE & Mean & SD & SE \\
\hline \multirow[t]{4}{*}{ DNA } & 7.2 & 765.94 & 100.73 & 58.16 & 2.83 & 0.35 & 0.20 & 0.01 & 0.00 & 0.00 \\
\hline & 7.4 & 494.74 & 323.31 & 186.66 & 3.30 & 0.25 & 0.15 & 0.04 & 0.02 & 0.01 \\
\hline & 7.8 & 492.58 & 260.52 & 150.41 & 2.54 & 0.66 & 0.38 & 0.02 & 0.02 & 0.00 \\
\hline & 8 & 410.36 & 142.16 & 82.08 & 3.38 & 0.43 & 0.25 & 0.03 & 0.00 & 0.00 \\
\hline \multirow[t]{4}{*}{ RNA } & 7.2 & 147.16 & 45.09 & 26.03 & 1.08 & 0.14 & 0.08 & 0.03 & 0.00 & 0.00 \\
\hline & 7.4 & 164.47 & 59.28 & 34.22 & 0.74 & 0.23 & 0.14 & 0.02 & 0.01 & 0.00 \\
\hline & 7.8 & 492.65 & 552.17 & 318.79 & 1.34 & 0.82 & 0.47 & 0.01 & 0.01 & 0.00 \\
\hline & 8 & 684.66 & 130.10 & 75.11 & 2.42 & 0.43 & 0.25 & 0.01 & 0.00 & 0.00 \\
\hline
\end{tabular}

TABLE 2 | Core microbiome of Stylophora pistillata kept in aquaria for 2 years at different pH treatments (7.2; 7.4, 7.8 and 8.0).

\begin{tabular}{|c|c|c|c|c|c|c|c|c|c|}
\hline \multirow[t]{2}{*}{ OTU } & \multirow[t]{2}{*}{ Taxon } & \multicolumn{4}{|c|}{ Average Abundance } & \multirow{2}{*}{$\begin{array}{c}\text { Relative } \\
\text { abundance\% }\end{array}$} & \multicolumn{3}{|c|}{ Blast on NCBI database } \\
\hline & & 7.2 & 7.4 & 7.8 & 8 & & Total score & Query cover & Identity \\
\hline Otu0002 & Thalassotalea & $1,295.7$ & $1,927.3$ & $2,312.3$ & $2,304.0$ & 18.37 & 536 & $98 \%$ & Thalassotalea sp. \\
\hline Otu0004 & Alteromonas & $2,703.7$ & $2,082.0$ & $1,368.7$ & 904.3 & 16.54 & 536 & $100 \%$ & Alteromonas marina \\
\hline Otu0005 & Flavobacteriacea & 218.0 & 81.7 & $2,946.3$ & $2,202.3$ & 12.77 & 527 & $100 \%$ & Flexibacter sp. \\
\hline Otu0008 & Alteromonas & 558.7 & 481.0 & 420.3 & 325.7 & 4.18 & 536 & $98 \%$ & Alteromonas sp. \\
\hline Otu0010 & Tenacibaculum & 354.7 & 626.0 & 271.0 & 271.7 & 3.57 & 525 & $100 \%$ & Tenacibaculum holothuriorum \\
\hline Otu0012 & Thalassolituus & 401.3 & 368.7 & 224.7 & 149.7 & 2.68 & 525 & $98 \%$ & Thalassolituus oleivorans \\
\hline Otu0011 & Kordia & 296.7 & 481.7 & 23.0 & 189.7 & 2.32 & 503 & $100 \%$ & Kordia sp. \\
\hline Otu0013 & Shimia & 375.0 & 182.3 & 171.7 & 132.3 & 2.02 & 531 & $98 \%$ & Shimia sp. \\
\hline Otu0014 & Thalassobius & 111.7 & 177.7 & 156.7 & 395.7 & 1.97 & 534 & $98 \%$ & Mameliella alba \\
\hline Otu0001 & Fulvivirga & 40.3 & 390.3 & 15.3 & 188.0 & 1.49 & 462 & $100 \%$ & Fulvivirga sp. \\
\hline Otu0018 & Salinimonas & 133.7 & 92.7 & 103.0 & 101.3 & 1.01 & 536 & $98 \%$ & Alteromonas sp. \\
\hline Otu0020 & Tenacibaculum & 12.7 & 47.7 & 177.0 & 140.3 & 0.88 & 496 & $100 \%$ & Tenacibaculum holothuriorum \\
\hline Otu0019 & Unclassified bacteria & 14.0 & 247.7 & 6.0 & 65.7 & 0.78 & 357 & $98 \%$ & Leptospira ryugenii \\
\hline Otu0023 & Oleiphilus & 64.7 & 82.7 & 64.0 & 93.3 & 0.71 & 492 & $100 \%$ & Oleiphilus sp. \\
\hline Otu0024 & Pelomonas & 10.3 & 125.7 & 12.0 & 152.7 & 0.70 & 538 & $98 \%$ & Pelomonas aquatica \\
\hline Otu0025 & Cutibacterium & 19.3 & 75.0 & 79.0 & 127.0 & 0.70 & 542 & $100 \%$ & Rhodococcus sp. \\
\hline Otu0027 & Pseudoalteromonas & 16.7 & 254.3 & 8.0 & 4.3 & 0.66 & 529 & $98 \%$ & Pseudoalteromonas sp. \\
\hline Otu0028 & Flavobacteriaceae & 15.7 & 3.7 & 202.0 & 55.3 & 0.65 & 510 & $100 \%$ & Polaribacter sp. \\
\hline Otu0031 & Endozoicomonas & 7.7 & 119.7 & 3.7 & 61.3 & 0.45 & 510 & $94 \%$ & Endozoicomonas sp. \\
\hline Otu0032 & Vibrio & 27.0 & 54.0 & 70.0 & 25.7 & 0.41 & 536 & $98 \%$ & Vibrio alginolyticus \\
\hline Otu0039 & Microscilla & 49.0 & 10.0 & 24.0 & 15.7 & 0.23 & 529 & $100 \%$ & Microscilla \\
\hline Otu0043 & Ruegeria & 9.7 & 33.0 & 22.0 & 16.3 & 0.19 & 534 & $98 \%$ & Ruegeria sp. \\
\hline Otu0095 & Rhodobacteraceae & 4.7 & 5.3 & 4.3 & 4.3 & 0.04 & 529 & $98 \%$ & Sulfitobacter sp. \\
\hline
\end{tabular}

Only DNA samples were considered when defining the core microbiome.

to holobiont functioning and health through the regulation of Symbiodiniaceae proliferation (Rädecker et al., 2015; Cui et al., 2019; Tilstra et al., 2019). In fact, previous studies using the same coral colonies did not observe a decrease in symbiont density with pH decrease (Tambutté et al., 2015). Consequently, a decrease in denitrifying bacteria at lower $\mathrm{pH}$ treatments could potentially impact nitrogen balance in coral holobionts.

Our LEfSe analysis indicated that Alteromonas sp. (OTU0008) and Lacimicrobium sp. (OTU0029) were representatives of the active community under control conditions at $\mathrm{pH} 8.0$, and nearly absent in lower $\mathrm{pH}$ treatments. Many species of the family Alteromonadaceae, especially Alteromonas, are sulfate reducers and known to be involved in DMSP metabolism (Raina et al., 2009), which is linked to osmoregulation and antioxidant capacity (Gardner et al., 2016; Hopkins et al., 2016). Previous studies also associated this genus with disease resistance (Wright et al., 2017). Thus, the decrease in abundance of members of this genus at low $\mathrm{pH}$ treatments could indicate loss in resilience and biogeochemical functions. Nonetheless, the functional role and ecological relevance of many bacterial taxa is still unknown, and this research area is essential for understanding holobiont functioning during stress. Even though $\mathrm{OA}$ can negatively 
influence microbial communities, the implication of those shifts on the host health, ecosystem function and adaptation or acclimation mechanisms are still being investigated. In contrast, we found that $\mathrm{OA}$ stimulated growth and activity of specific OTUs, such as unclassified Cellvibrionaceae (OTU0006, 98.28\% identical to Exilibacterium tricleocarpae, GenBank accession no. MN094885.1). This OTU was present in low abundance in the resident community, suggesting that it might represent an opportunistic bacterium that increased in activity in response to acidification in low $\mathrm{pH}$ treatments.

Interestingly, richness and diversity in the resident community did not differ statistically between treatments, and remained high even in low $\mathrm{pH}$ treatments, suggesting that many bacterial taxa remain in the community after environmental change as dormant members. Dormancy plays an important role in shaping bacterial communities and is a well-known strategy used by many organisms to survive through unfavorable conditions (Sussman and Douthit, 1973). Previous studies indicate that dormant bacteria can account for high proportion of taxa in stressed ecosystems (Jones and Lennon, 2010). Some resident representative OTUs identified by LEfSe analysis at $\mathrm{pH} 7.2$ were members of the phylum Bacteroidetes, including the genus Tenacibaculum (OTU0279), a known fish pathogen (Faílde et al., 2013) and members of the Flavobacteriaceae family (OTU0041 and OTU0375). A higher abundance of Bacteroidetes has been reported previously for corals under low $\mathrm{pH}$ conditions (Thurber et al., 2009; Meron et al., 2011; Morrow et al., 2015) and in diseased coral (Bourne et al., 2009). Similarly, three indicator species for $\mathrm{pH} 7.2$ were from the order Alteromonadales, which encompass some potential coral pathogens (Krediet et al., 2013; Roder et al., 2014).

Thus, a change in OA can induce shifts in the bacterial community by inhibiting activity of many taxa while stimulating activity of a few specific, potentially opportunistic, taxa previously resident in low abundances. Despite the identified changes on microbial community composition in response to $\mathrm{OA}$, the implications for host health are still unknown. In fact, changes in the coral microbiome due to environmental stress do not necessarily reflect holobiont stress, but could even reflect potential acclimation responses. Thus, more studies should be conducted to investigate consistent patterns in microbiome changes associated with environmental stressors, as well as acclimation potential and ecological functions of key microbial taxa in coral phenotypes.

\section{Core Microbiome of Stylophora pistillata}

To study patterns in microbiome composition, previous studies have focused on the core microbiome, which is defined as the members consistently shared among microbial consortia from similar habitats (Shade and Handelsman, 2012). Usually, the coral microbiome has a core species-specific bacterial group and a transient group that changes according to environmental parameters such as climate and geography (Ritchie, 2006).

S. pistillata has previously been shown to have specific associations with species from the genus Endozoicomonas (Bayer et al., 2013; Neave et al., 2017) and we also identify them as part of the core microbiome in this study (Table 2). However, their abundance is lower than reported in studies using colonies sampled from the wild, potentially due to the long-term rearing of the colonies used here in an aquarium environment. Coral microbiome studies greatly depend on corals maintained in aquariums that simulate natural conditions, but the effects of captivity on the coral microbiome are understudied. Previous research has observed differences in the microbiome of corals between colonies in situ and those reared in aquaria. For instance, shifts on the surface mucus layer (SML) microbiome were reported for Fungia granulosa (Kooperman et al., 2007) and Siderastrea siderea after as early as 1 day of aquarium rearing (Pratte et al., 2015). In the coral Lophelia pertusa, both skeleton and SML were different between in situ and ex situ habitats (Schöttner et al., 2009). In Eguchipsammia fistula, the associated microbiome also differed between native and aquarium settings. Functional profiling suggested that processes related to carbonand nitrogen-limited environments were enriched in the native habitat, which could reflect diet changes between in situ and aquarium conditions (Röthig et al., 2017). Galand et al. (2018) investigated microbiome changes in aquaria across different time points, both on the active (rRNA) and resident (rDNA) fraction. Their results suggest a species-specific response. For Madrepora oculata, bacterial associations remained stable for at least 6 months of captivity, which is in agreement with a stable bacterial community in aquarium-reared Acropora loripes over 4 weeks (Hill and Ralph, 2006; Damjanovic et al., 2020). Interestingly, Galand et al. (2018) further found that the abundance of Endozoicomonas in the RNA fraction decreased after only 1 day of captivity but started to increase again after 5 days. For Lophelia pertusa, they observed microbiome changes after only 1 day of aquarium rearing. Some taxa disappeared completely and other appeared only after months in aquaria, which the authors considered an aquarium signature. They further concluded that opportunistic bacteria might colonize corals in captivity. Thus, considering the long-term nature of this study's experimental setup, with corals kept in captivity for several decades, it is possible that their microbiomes diverged significantly from the ones found in natural environments. This illustrates a potential limitation of using aquarium specimens for microbial community studies, since it will limit the presence of potentially ecological relevant bacterial taxa associated to geographical location.

\section{Importance of the Active Microbiome}

In this study, we identified bacterial taxa with low relative abundance on DNA level, but high abundance on RNA level, indicating rare but highly active community members. The existence of a large diverse microbial community, with few abundant and many rare taxa is common in the natural environment (Sogin et al., 2006). While the relationship between bacterial abundance and activity is still unclear, one common hypothesis for this distribution is that abundant bacteria have high growth rates, while rare taxa are slow growing (Pedrós-Alió, 2006). However, multiple studies have found rare bacteria taxa to be disproportionally active and displaying high growth rates (Jones and Lennon, 2010; Campbell et al., 2011; Weigold et al., 2016). 
There is an increasing number of studies highlighting the importance of rare bacterial taxa (Sogin et al., 2006; PedrósAlió, 2007, 2012; D Ainsworth et al., 2015; Lynch and Neufeld, 2015; Jousset et al., 2017). These often underrated and unexplored species may represent a source of genetic novelty in times of environmental change. Some might even be keystone species, being essential to understand community composition and function (Sogin et al., 2006; Elshahed et al., 2008).

\section{CONCLUSION}

The use of $16 \mathrm{~S}$ rDNA sequencing to study bacterial communities is widespread. However, only few studies use 16S rRNA sequencing, which means much is unknown about the correlation between microbial activity and composition, particularly for coral holobionts. We show that OA can significantly impact the resident coral microbiome, although a stronger effect was observed on the active microbial community, which suggests that the microbial community responded primarily to the environmental change through modified activity patterns. Importantly, we also found that low $\mathrm{pH}$ might play a role in the shift of bacterial OTUs from active to dormant states and vice versa, allowing opportunistic bacteria to increase in activity while reducing the abundance of some members of the core microbiome. The microbiome is a critical component of coral resilience, and this study provides insights into the effects of ocean acidification on coral bacterial community composition and coral holobiont response to climate change. Moreover, our study confirms that rDNA and rRNA based sequencing can result in different community composition, with the RNA-based community reflecting the metabolically active population. Our analysis also showed that some low abundant resident bacterial taxa were highly active, suggesting they could play key functional roles. Thus, both methods, rDNA and rRNA sequencing, should be considered complementary tools to investigate microbial assemblage structure and activity.

\section{DATA AVAILABILITY STATEMENT}

The datasets presented in this study can be found in online repositories. The names of the repository/repositories and

\section{REFERENCES}

Acinas, S. G., Sarma-Rupavtarm, R., Klepac-Ceraj, V., and Polz, M. F. (2005). PCRinduced sequence artifacts and bias: insights from comparison of two 16S rRNA clone libraries constructed from the same sample. Appl. Environ. Microbiol. 71, 8966-8969. doi: 10.1128/AEM.71.12.8966-8969.2005

Andersson, A. F., Lindberg, M., Jakobsson, H., Bäckhed, F., Nyrén, P., and Engstrand, L. (2008). Comparative analysis of human gut microbiota by barcoded pyrosequencing. PLoS One 3:e2836. doi: 10.1371/journal.pone. 0002836

Anthony, K. R. N., Kline, D. I., Diaz-Pulido, G., Dove, S., and Hoegh-Guldberg, O. (2008). Ocean acidification causes bleaching and productivity loss in coral reef builders. Proc. Natl. Acad. Sci. U.S.A. 105, 17442-17446. doi: 10.1073/pnas. 0804478105 accession number(s) can be found below: https://www.ebi.ac.uk/ ena, PRJEB44699.

\section{AUTHOR CONTRIBUTIONS}

DZ, ST, DA, ET, and AV performed the experiment in Monaco. $\mathrm{MZ}, \mathrm{CV}$, and MA designed the study. MB performed laboratory work, analyzed the data, and wrote the first draft of the manuscript. CA contributed to the bioinformatics analysis. All authors contributed to the writing and editing of the manuscript and read and approved the final manuscript.

\section{FUNDING}

This study was supported by the KAUST Office of Sponsored Research under award no. FCC/1/1973-2201 and the Center Scientifique de Monaco Research Program, which is supported by the Government of the Principality of Monaco.

\section{ACKNOWLEDGMENTS}

We would like to thank D. Desgre, N. Caminiti-Segonds, and $\mathrm{N}$. Techer for assistance in coral husbandry. We would also like to thank the Visiting Student Research Program of King Abdullah University of Science and Technology for funding, Marcela Herrera for library preparation assistance, Lucia Pombo for advice on statistics, and KAUST Bioscience Core Laboratory for library sequencing.

\section{SUPPLEMENTARY MATERIAL}

The Supplementary Material for this article can be found online at: https://www.frontiersin.org/articles/10.3389/fmicb. 2021.707674/full\#supplementary-material

Baldrian, P., Kolařík, M., Stursová, M., Kopecký, J., Valášková, V., Větrovský, T., et al. (2012). Active and total microbial communities in forest soil are largely different and highly stratified during decomposition. ISME J. 6, 248-258. doi: 10.1038/ismej.2011.95

Bayer, T., Neave, M. J., Alsheikh-Hussain, A., Aranda, M., Yum, L. K., Mincer, T., et al. (2013). The microbiome of the red sea coral stylophora pistillata is dominated by tissue-associated endozoicomonas bacteria. Appl. Environ. Microbiol. 79, 4759-4762. doi: 10.1128/AEM.00695-13

Berdjeb, L., Pollet, T., Domaizon, I., and Jacquet, S. (2011). Effect of grazers and viruses on bacterial community structure and production in two contrasting trophic lakes. BMC Microbiol. 11:88. doi: 10.1186/1471-2180-11-88

Blagodatskaya, E., and Kuzyakov, Y. (2013). Active microorganisms in soil: critical review of estimation criteria and approaches. Soil Biol. Biochem. 67, 192-211. doi: 10.1016/J.SOILBIO.2013.08.024 
Blazewicz, S. J., Barnard, R. L., Daly, R. A., and Firestone, M. K. (2013). Evaluating rRNA as an indicator of microbial activity in environmental communities: limitations and uses. ISME J. 7, 2061-2068. doi: 10.1038/ismej.2013.102

Bourne, D. G., Garren, M., Work, T. M., Rosenberg, E., Smith, G. W., and Harvell, C. D. (2009). Microbial disease and the coral holobiont. Trends Microbiol. 17, 554-562. doi: 10.1016/J.TIM.2009.09.004

Campbell, B. J., Yu, L., Heidelberg, J. F., and Kirchman, D. L. (2011). Activity of abundant and rare bacteria in a coastal ocean. Proc. Natl. Acad. Sci. U.S.A. 108, 12776-12781. doi: 10.1073/pnas.1101405108

Carini, P., Marsden, P. J., Leff, J. W., Morgan, E. E., Strickland, M. S., and Fierer, N. (2016). Relic DNA is abundant in soil and obscures estimates of soil microbial diversity. Nat. Microbiol. 2, 1-6. doi: 10.1038/nmicrobiol.2016.242

Clarke, K. R. (1993). Non-parametric multivariate analyses of changes in community structure. Austral. Ecol. 18, 117-143. doi: 10.1111/j.1442-9993. 1993.tb00438.x

Clarke, K. R., and Gorley, R. N. (2006). PRIMER V6: User Manual/Tutorial. Plymouth: PRIMER-E.

Cui, G., Liew, Y. J., Li, Y., Kharbatia, N., Zahran, N. I., Emwas, A.-H., et al. (2019). Host-dependent nitrogen recycling as a mechanism of symbiont control in Aiptasia. PLoS Genet. 15:e1008189. doi: 10.1371/journal.pgen.1008189

D Ainsworth, T., Krause, L., Bridge, T., Torda, G., Raina, J.-B., Zakrzewski, M., et al. (2015). The coral core microbiome identifies rare bacterial taxa as ubiquitous endosymbionts. ISME J. 9, 2261-2274. doi: 10.1038/ismej.2015.39

Damjanovic, K., Blackall, L. L., Peplow, L. M., and van Oppen, M. J. H. (2020). Assessment of bacterial community composition within and among Acropora loripes colonies in the wild and in captivity. Coral Reefs 39, 1245-1255. doi: 10.1007/s00338-020-01958-y

DeAngelis, K. M., and Firestone, M. K. (2012). Phylogenetic clustering of soil microbial communities by $16 \mathrm{~S}$ rRNA but not $16 \mathrm{~S}$ rRNA genes. Appl. Environ. Microbiol. 78, 2459-2461. doi: 10.1128/AEM.07547-11

Dlott, G., Maul, J. E., Buyer, J., and Yarwood, S. (2015). Microbial rRNA: RDNA gene ratios may be unexpectedly low due to extracellular DNA preservation in soils. J. Microbiol. Methods 115, 112-120. doi: 10.1016/j.mimet.2015.05.027

Doney, S. C., Fabry, V. J., Feely, R. A., and Kleypas, J. A. (2009). Ocean acidification: the other CO 2 problem. Ann. Rev. Mar. Sci. 1, 169-192. doi: 10.1146/annurev. marine.010908.163834

Duineveld, B. M., Kowalchuk, G. A., Keijzer, A., van Elsas, J. D., and van Veen, J. A. (2001). Analysis of bacterial communities in the rhizosphere of chrysanthemum via denaturing gradient gel electrophoresis of PCR-amplified 16S rRNA as well as DNA fragments coding for 16S rRNA. Appl. Environ. Microbiol. 67, 172-178. doi: 10.1128/AEM.67.1.172-178.2001

Edgar, R. C., Haas, B. J., Clemente, J. C., Quince, C., and Knight, R. (2011). UCHIME improves sensitivity and speed of chimera detection. Bioinformatics 27, 2194-2200. doi: 10.1093/bioinformatics/btr381

Ellis, S., Howe, M. T., Goulding, K. W. T., Mugglestone, M. A., and Dendooven, L. (1998). Carbon and nitrogen dynamics in a grassland soil with varying $\mathrm{pH}$ : effect of $\mathrm{pH}$ on the denitrification potential and dynamics of the reduction enzymes. Soil Biol. Biochem. 30, 359-367. doi: 10.1016/S0038-0717(97)00122-3

Elshahed, M. S., Youssef, N. H., Spain, A. M., Sheik, C., Najar, F. Z., Sukharnikov, L. O., et al. (2008). Novelty and uniqueness patterns of rare members of the soil biosphere. Appl. Environ. Microbiol. 74, 5422-5428. doi: 10.1128/AEM.004 10-08

Faílde, L. D., Losada, A. P., Bermúdez, R., Santos, Y., and Quiroga, M. I. (2013). Tenacibaculum maritimum infection: pathology and immunohistochemistry in experimentally challenged turbot (Psetta maxima L.). Microb. Pathog. 65, 82-88. doi: 10.1016/J.MICPATH.2013.09.003

Gaidos, E., Rusch, A., and Ilardo, M. (2011). Ribosomal tag pyrosequencing of DNA and RNA from benthic coral reef microbiota: community spatial structure, rare members and nitrogen-cycling guilds. Environ. Microbiol. 13, 1138-1152. doi: 10.1111/j.1462-2920.2010.02392.x

Galand, P. E., Chapron, L., Meistertzheim, A.-L., Peru, E., and Lartaud, F. (2018). The effect of captivity on the dynamics of active bacterial communities differs between two deep-sea coral species. Front. Microbiol. 9:2565. doi: 10.3389/ fmicb.2018.02565

Gardner, S. G., Nielsen, D. A., Laczka, O., Shimmon, R., Beltran, V. H., Ralph, P. J., et al. (2016). Dimethylsulfoniopropionate, superoxide dismutase and glutathione as stress response indicators in three corals under short-term hyposalinity stress. Proc. R. Soc. B Biol. Sci. 283:20152418. doi: 10.1098/rspb. 2015.2418

Grottoli, A. G., Martins, P. D., Wilkins, M. J., Johnston, M. D., Warner, M. E., Cai, W. J., et al. (2018). Coral physiology and microbiome dynamics under combined warming and ocean acidification. PLoS One 13:e0191156. doi: 10. 1371/journal.pone.0191156

Hill, R., and Ralph, P. J. (2006). Photosystem II heterogeneity of in hospite zooxanthellae in scleractinian corals exposed to bleaching conditions. Photochem. Photobiol. 82:1577. doi: 10.1562/2006-04-13-RA-871

Hoegh-Guldberg, O., et al. (2007). Coral reefs under rapid climate change and ocean acidification. Science 318:1737. doi: 10.1126/science.1137094

Hopkins, F., Bell, T., Yang, M., Suggett, D., and Steinke, M. (2016). Air exposure of coral is a significant source of dimethylsulfide (DMS) to the atmosphere. Sci. Rep. 6:36031. doi: 10.1038/SREP36031

Hoshino, Y. T., and Matsumoto, N. (2007). DNA- versus RNA-based denaturing gradient gel electrophoresis profiles of a bacterial community during replenishment after soil fumigation. Soil Biol. Biochem. 39, 434-444. doi: 10. 1016/J.SOILBIO.2006.08.013

Hughes, T., Barnes, M. L., Bellwood, D. R., Cinner, J. E., Cumming, G. S., Jackson, J. B. C., et al. (2017). Coral reefs in the anthropocene. Nature 546:82.

Hunt, D. E., Lin, Y., Church, M. J., Karl, D. M., Tringe, S. G., Izzo, L. K., et al. (2013). Relationship between abundance and specific activity of bacterioplankton in open ocean surface waters. Appl. Environ. Microbiol. 79, 177-184. doi: 10.1128/ AEM.02155-12

Huse, S. M., Welch, D. M., Morrison, H. G., and Sogin, M. L. (2010). Ironing out the wrinkles in the rare biosphere through improved OTU clustering. Environ. Microbiol. 12:1889. doi: 10.1111/J.1462-2920.2010.02193.X

Jones, S. E., and Lennon, J. T. (2010). Dormancy contributes to the maintenance of microbial diversity. Proc. Natl. Acad. Sci. U.S.A. 107, 5881-5886. doi: 10.1073/ pnas.0912765107

Jousset, A., Bienhold, C., Chatzinotas, A., Gallien, L., Gobet, A., Kurm, V., et al. (2017). Where less may be more: how the rare biosphere pulls ecosystems strings. ISME J. 11, 853-862. doi: 10.1038/ismej.2016.174

Kooperman, N., Ben-Dov, E., Kramarsky-Winter, E., Barak, Z., and Kushmaro, A. (2007). Coral mucus-associated bacterial communities from natural and aquarium environments. FEMS Microbiol. Lett. 276, 106-113. doi: 10.1111/j. 1574-6968.2007.00921.x

Krediet, C. J., Ritchie, K. B., Paul, V. J., and Teplitski, M. (2013). Coral-associated micro-organisms and their roles in promoting coral health and thwarting diseases. Proc. R. Soc. B Biol. Sci. 280:20122328. doi: 10.1098/rspb.2012.2328

LaJeunesse, T. C., Parkinson, J. E., Gabrielson, P. W., Jeong, H. J., Reimer, J. D., Voolstra, C. R., et al. (2018). Systematic revision of symbiodiniaceae highlights the antiquity and diversity of coral endosymbionts. Curr. Biol. 28, 2570-2580.e6. doi: 10.1016/J.CUB.2018.07.008

Lane, D. J., Pace, B., Olsen, G. J., Stahl, D. A., Sogin, M. L., and Pace, N. R. (1985). Rapid determination of 16 S ribosomal RNA sequences for phylogenetic analyses. Proc. Natl. Acad. Sci. U.S.A. 82, 6955-6959. doi: 10.1073/pnas.82.20. 6955

Lanzén, A., Jørgensen, S. L., Bengtsson, M. M., Jonassen, I., Øvreås, L., and Urich, T. (2011). Exploring the composition and diversity of microbial communities at the jan mayen hydrothermal vent field using RNA and DNA. FEMS Microbiol. Ecol. 77, 577-589. doi: 10.1111/j.1574-6941.2011.01138.x

Lema, K. A., Willis, B. L., and Bourneb, D. G. (2012). Corals form characteristic associations with symbiotic nitrogen-fixing bacteria. Appl. Environ. Microbiol. 78, 3136-3144. doi: 10.1128/AEM.07800-11

Lesser, M. P., Mazel, C. H., Gorbunov, M. Y., and Falkowski, P. G. (2004). Discovery of symbiotic nitrogen-fixing cyanobacteria in corals. Science 305, 997-1000. doi: $10.1126 /$ science. 1099128

Li, M.-Y., Yang, Y.-H., Mi, T.-Z., He, H., and Zhen, Y. (2020). Differences between DNA- and RNA-based bacterial communities in marine sediments. Huan Jing Ke Xue 41, 2485-2495. doi: 10.13227/j.hjkx.201911071

Liew, Y. J., Zoccola, D., Li, Y., Tambutté, E., Venn, A. A., Michell, C. T., et al. (2018). Epigenome-associated phenotypic acclimatization to ocean acidification in a reef-building coral. Sci. Adv. 4:eaar8028. doi: 10.1126/sciadv.aar8028

Lillis, L., Doyle, E., and Clipson, N. (2009). Comparison of DNA- and RNA-based bacterial community structures in soil exposed to 2,4-dichlorophenol. J. Appl. Microbiol. 107, 1883-1893. doi: 10.1111/j.1365-2672.2009.04369.x 
Lynch, M. D. J., and Neufeld, J. D. (2015). Ecology and exploration of the rare biosphere. Nat. Rev. Microbiol. 13, 217-229. doi: 10.1038/nrmicro3400

McCarthy, A., Chiang, E., Schmidt, M. L., and Denef, V. J. (2015). RNA preservation agents and nucleic acid extraction method bias perceived bacterial community composition. PLoS One 10:e0121659. doi: 10.1371/journal.pone. 0121659

McDonald, D., Price, M. N., Goodrich, J., Nawrocki, E. P., DeSantis, T. Z., Probst, A., et al. (2012). An improved greengenes taxonomy with explicit ranks for ecological and evolutionary analyses of bacteria and archaea. ISME J. 6, 610-618. doi: 10.1038/ismej.2011.139

Mengoni, A., Tatti, E., Decorosi, F., Viti, C., Bazzicalupo, M., and Giovannetti, L. (2005). Comparison of $16 \mathrm{~S}$ rRNA and $16 \mathrm{~S}$ rDNA T-RFLP approaches to study bacterial communities in soil microcosms treated with chromate as perturbing agent. Microb. Ecol. 50, 375-384. doi: 10.1007/s00248-004-0222-4

Meron, D., Atias, E., Iasur Kruh, L., Elifantz, H., Minz, D., Fine, M., et al. (2011). The impact of reduced $\mathrm{pH}$ on the microbial community of the coral Acropora eurystoma. ISME J. 5, 51-60. doi: 10.1038/ismej.2010.102

Meron, D., Rodolfo-Metalpa, R., Cunning, R., Baker, A. C., Fine, M., and Banin, E. (2012). Changes in coral microbial communities in response to a natural $\mathrm{pH}$ gradient. ISME J. 6, 1775-1785. doi: 10.1038/ismej.2012.19

Moberg, F., and Folke, C. (1999). Ecological goods and services of coral reef ecosystems. Ecol. Econ. 29, 215-233. doi: 10.1016/S0921-8009(99)00009-9

Morrow, K. M., Bourne, D. G., Humphrey, C., Botté, E. S., Laffy, P., Zaneveld, J., et al. (2015). Natural volcanic CO2 seeps reveal future trajectories for hostmicrobial associations in corals and sponges. ISME J. 9, 894-908. doi: 10.1038/ ismej. 2014.188

Neave, M. J., Rachmawati, R., Xun, L., Michell, C. T., Bourne, D. G., Apprill, A., et al. (2017). Differential specificity between closely related corals and abundant Endozoicomonas endosymbionts across global scales. ISME J. 11, 186-200. doi: 10.1038/ismej.2016.95

Nogales, B., Moore, E. R., Llobet-Brossa, E., Rossello-Mora, R., Amann, R., and Timmis, K. N. (2001). Combined use of 16 S ribosomal DNA and 16S rRNA to study the bacterial community of polychlorinated biphenyl-polluted soil. Appl. Environ. Microbiol. 67, 1874-1884. doi: 10.1128/AEM.67.4.1874-1884.2001

O’Brien, P. A., Morrow, K. M., Willis, B. L., and Bourne, D. G. (2016). Implications of ocean acidification for marine microorganisms from the free-living to the host-associated. Front. Mar. Sci. 3:47. doi: 10.3389/fmars.2016.00047

O’Brien, P. A., Smith, H. A., Fallon, S., Fabricius, K., Willis, B. L., Morrow, K. M., et al. (2018). Elevated CO2 has little influence on the bacterial communities associated with the $\mathrm{pH}$-tolerant coral, massive Porites spp. Front. Microbiol. 9:2621. doi: 10.3389/fmicb.2018.02621

Pedrós-Alió, C. (2006). Marine microbial diversity: can it be determined? Trends Microbiol. 14, 257-263. doi: 10.1016/J.TIM.2006.04.007

Pedrós-Alió, C. (2007). Dipping into the rare biosphere. Science 315, 192-193. doi: 10.1126/science.1136264

Pedrós-Alió, C. (2012). The rare bacterial biosphere. Ann. Rev. Mar. Sci. 4, 449-466. doi: 10.1146/annurev-marine-120710-100948

Pietramellara, G., Ascher, J., Borgogni, F., Ceccherini, M. T., Guerri, G., and Nannipieri, P. (2009). Extracellular DNA in soil and sediment: fate and ecological relevance. Biol. Fert. Soils 45, 219-235. doi: 10.1007/s00374-0080345-8

Pogoreutz, C., Rädecker, N., Cárdenas, A., Gärdes, A., Voolstra, C. R., and Wild, C. (2017a). Sugar enrichment provides evidence for a role of nitrogen fixation in coral bleaching. Glob. Change Biol. 23, 3838-3848. doi: 10.1111/gcb.13695

Pogoreutz, C., Rädecker, N., Cárdenas, A., Gärdes, A., Wild, C., and Voolstra, C. R. (2017b). Nitrogen fixation aligns with nifH abundance and expression in two coral trophic functional groups. Front. Microbiol. 8:1187. doi: 10.3389/fmicb. 2017.01187

Poulsen, L. K., Ballard, G., and Stahl, D. A. (1993). Use of rRNA fluorescence in situ hybridization for measuring the activity of single cells in young and established biofilms. Appl. Environ. Microbiol. 59, 1354-1360.

Pratte, Z. A., Richardson, L. L., and Mills, D. K. (2015). Microbiota shifts in the surface mucopolysaccharide layer of corals transferred from natural to aquaria settings. J. Invertebr. Pathol. 125, 42-44. doi: 10.1016/J.JIP.2014.12.009

Pruesse, E., Quast, C., Knittel, K., Fuchs, B. M., Ludwig, W., Peplies, J., et al. (2007). SILVA: a comprehensive online resource for quality checked and aligned ribosomal RNA sequence data compatible with ARB. Nucleic Acids Res. 35, 7188-7196. doi: 10.1093/nar/gkm864
Rädecker, N., Pogoreutz, C., Voolstra, C. R., Wiedenmann, J., and Wild, C. (2015). Nitrogen cycling in corals: the key to understanding holobiont functioning? Trends Microbiol. 23, 490-497. doi: 10.1016/J.TIM.2015.03.008

Raina, J.-B., Tapiolas, D., Willis, B. L., and Bourne, D. G. (2009). Coral-associated bacteria and their role in the biogeochemical cycling of sulfur. Appl. Environ. Microbiol. 75, 3492-3501. doi: 10.1128/AEM.02567-08

Ramos, C., Mølbak, L., and Molin, S. (2000). Bacterial activity in the rhizosphere analyzed at the single-cell level by monitoring ribosome contents and synthesis rates. Appl. Environ. Microbiol. 66, 801-809. doi: 10.1128/aem.66.2.801-809. 2000

Reaka-Kudla, M. L. (2001). "Known and unknown biodiversity, risk of extinction and conservation strategy in the sea," in Waters in Peril, eds L. Bendell-Young and P. Gallaugher (Boston, MA: Springer), 19-33. doi: 10.1007/978-1-46151493-0_2

Rhein, M. (2014). "Observations: ocean pages," in Chapter 3, Observations: Oceans, in IPCC 2013, Climate Change 2013 - The Physical Science Basis, ed. Intergovernmental Panel on Climate Change (Cambridge: Cambridge University Press), 255-316. doi: 10.1017/CBO9781107415324.010

Ritchie, K. (2006). Regulation of microbial populations by coral surface mucus and mucus-associated bacteria. Mar. Ecol. Prog. Ser. 322, 1-14. doi: 10.3354/ meps322001

Robbins, S. J., Singleton, C. M., Chan, C. X., Messer, L. F., Geers, A. U., Ying, H., et al. (2019). A genomic view of the reef-building coral Porites lutea and its microbial symbionts. Nat. Microbiol. 4, 2090-2100. doi: 10.1038/s41564-0190532-4

Roder, C., Arif, C., Daniels, C., Weil, E., and Voolstra, C. R. (2014). Bacterial profiling of white plague disease across corals and oceans indicates a conserved and distinct disease microbiome. Mol. Ecol. 23, 965-974. doi: 10.1111/mec. 12638

Rohwer, F., Seguritan, V., Azam, F., and Knowlton, N. (2002). Diversity and distribution of coral-associated bacteria. Mar. Ecol. Prog. Ser. 243, 1-10. doi: $10.3354 /$ meps243001

Romanowicz, K. J., Freedman, Z. B., Upchurch, R. A., Argiroff, W. A., and Zak, D. R. (2016). Active microorganisms in forest soils differ from the total community yet are shaped by the same environmental factors: the influence of pH and soil moisture. FEMS Microbiol. Ecol. 92:fiw149. doi: 10.1093/femsec/ fiw149

Rosenberg, E. (2013). The Prokaryotes: Alphaproteobacteria and Betaproteobacteria. Berlin: Springer, 1-1012. doi: 10.1007/978-3-642-30197-1

Rosenberg, E., Koren, O., Reshef, L., Efrony, R., and Zilber-Rosenberg, I. (2007). The role of microorganisms in coral health, disease and evolution. Nat. Rev. Microbiol. 5, 355-362. doi: 10.1038/nrmicro1635

Röthig, T., Roik, A., Yum, L. K., and Voolstra, C. R. (2017). Distinct bacterial microbiomes associate with the Deep-Sea Coral Eguchipsammia fistula from the red sea and from aquaria settings. Front. Mar. Sci. 4:259. doi: 10.3389/fmars. 2017.00259

Salgar-Chaparro, S. J., and Machuca, L. L. (2019). Complementary DNA/RNAbased profiling: characterization of corrosive microbial communities and their functional profiles in an oil production facility. Front. Microbiol. 10:2587. doi: 10.3389/fmicb.2019.02587

Schloss, P. D., Westcott, S. L., Ryabin, T., Hall, J. R., Hartmann, M., Hollister, E. B., et al. (2009). Introducing mothur: open-source, platform-independent, community-supported software for describing and comparing microbial communities. Appl. Environ. Microbiol. 75, 7537-7541. doi: 10.1128/AEM. 01541-09

Schöttner, S., Hoffmann, F., Wild, C., Rapp, H. T., Boetius, A., and Ramette, A. (2009). Inter- and intra-habitat bacterial diversity associated with cold-water corals. ISME J. 3, 756-759. doi: 10.1038/ismej.2009.15

Segata, N., Izard, J., Waldron, L., Gevers, D., Miropolsky, L., Garrett, W. S., et al. (2011). Metagenomic biomarker discovery and explanation. Genome Biol. 12:R60. doi: 10.1186/gb-2011-12-6-r60

Shade, A., and Handelsman, J. (2012). Beyond the venn diagram: the hunt for a core microbiome. Environ. Microbiol. 14, 4-12. doi: 10.1111/j.1462-2920.2011. 02585.x

Sogin, M. L., Morrison, H. G., Huber, J. A., Mark Welch, D., Huse, S. M., Neal, P. R., et al. (2006). Microbial diversity in the deep sea and the underexplored \&quot;rare biosphere\&quot. Proc. Natl. Acad. Sci. U.S.A. 103, 12115-12120. doi: $10.1073 /$ pnas. 0605127103 
Steven, B., Hesse, C., Soghigian, J., Gallegos-Graves, L. V., and Dunbar, J. (2017). Simulated ribosomal RNA:DNA ratios show potential to misclassify active populations as dormant. Appl. Environ. Microbiol. 83, e00696-17. doi: 10.1128/ AEM.00696-17

Sussman, A. S., and Douthit, H. A. (1973). Dormancy in Microbial Spores. Available online at: www.annualreviews.org (accessed February 27, 2021)

Tambutté, E., Venn, A. A., Holcomb, M., Segonds, N., Techer, N., Zoccola, D., et al. (2015). Morphological plasticity of the coral skeleton under CO2-driven seawater acidification. Nat. Commun. 6:7368. doi: 10.1038/ncomms8368

Thörn, M., and Sörensson, F. (1996). Variation of nitrous oxide formation in the denitrification basin in a wastewater treatment plant with nitrogen removal. Water Res. 30, 1543-1547. doi: 10.1016/0043-1354(95)00327-4

Thurber, R. V., Willner-Hall, D., Rodriguez-Mueller, B., Desnues, C., Edwards, R. A., Angly, F., et al. (2009). Metagenomic analysis of stressed coral holobionts. Environ. Microbiol. 11, 2148-2163. doi: 10.1111/j.1462-2920.2009.01935.x

Tilstra, A., El-Khaled, Y. C., Roth, F., Rädecker, N., Pogoreutz, C., Voolstra, C. R., et al. (2019). Denitrification aligns with N2 fixation in red sea corals. Sci. Rep. 9:19460. doi: 10.1038/s41598-019-55408-z

Venn, A. A., Tambutté, E., Holcomb, M., Laurent, J., Allemand, D., and Tambutté, S. (2013). Impact of seawater acidification on $\mathrm{pH}$ at the tissue-skeleton interface and calcification in reef corals. Proc. Natl. Acad. Sci. U.S.A. 110, 1634-1639. doi: 10.1073/PNAS.1216153110

Voolstra, C. R., and Ziegler, M. (2020). Adapting with microbial help: microbiome flexibility facilitates rapid responses to environmental change. Bioessays 42:2000004. doi: 10.1002/bies.202000004

Webster, N. S., Negri, A. P., Botté, E. S., Laffy, P. W., Flores, F., Noonan, S., et al. (2016). Host-associated coral reef microbes respond to the cumulative pressures of ocean warming and ocean acidification. Sci. Rep. 6:19324. doi: $10.1038 /$ srep 19324

Webster, N. S., Negri, A. P., Flores, F., Humphrey, C., Soo, R., Botté, E. S., et al. (2013). Near-future ocean acidification causes differences in microbial associations within diverse coral reef taxa. Environ. Microbiol. Rep. 5, 243-251. doi: 10.1111/1758-2229.12006

Weigold, P., Ruecker, A., Loesekann-Behrens, T., Kappler, A., and Behrens, S. (2016). Ribosomal tag pyrosequencing of DNA and RNA reveals "rare" taxa with high protein synthesis potential in the sediment of a hypersaline lake in
Western Australia. Geomicrobiol. J. 33, 426-440. doi: 10.1080/01490451.2015. 1049304

Weisburg, W. G., Barns, S. M., Pelletier, D. A., and Lane, D. J. (1991). 16S ribosomal DNA amplification for phylogenetic study. J. Bacteriol. 173, 697-703. doi: 10.1128/jb.173.2.697-703.1991

Wright, R. M., Kenkel, C. D., Dunn, C. E., Shilling, E. N., Bay, L. K., and Matz, M. V. (2017). Intraspecific differences in molecular stress responses and coral pathobiome contribute to mortality under bacterial challenge in Acropora millepora. Sci. Rep. 7:2609. doi: 10.1038/s41598-01702685-1

Yang, S., Sun, W., Zhang, F., and Li, Z. (2013). Phylogenetically diverse denitrifying and ammonia-oxidizing bacteria in corals Alcyonium gracillimum and Tubastraea coccinea. Mar. Biotechnol. 15, 540-551. doi: 10.1007/s10126013-9503-6

Zhou, G., Yuan, T., Cai, L., Zhang, W., Tian, R., Tong, H., et al. (2016). Changes in microbial communities, photosynthesis and calcification of the coral Acropora gemmifera in response to ocean acidification. Sci. Rep. 6:35971. doi: 10.1038/ srep35971

Conflict of Interest: The authors declare that the research was conducted in the absence of any commercial or financial relationships that could be construed as a potential conflict of interest.

Publisher's Note: All claims expressed in this article are solely those of the authors and do not necessarily represent those of their affiliated organizations, or those of the publisher, the editors and the reviewers. Any product that may be evaluated in this article, or claim that may be made by its manufacturer, is not guaranteed or endorsed by the publisher.

Copyright (c) 2021 Barreto, Ziegler, Venn, Tambutté, Zoccola, Tambutté, Allemand, Antony, Voolstra and Aranda. This is an open-access article distributed under the terms of the Creative Commons Attribution License (CC BY). The use, distribution or reproduction in other forums is permitted, provided the original author(s) and the copyright owner(s) are credited and that the original publication in this journal is cited, in accordance with accepted academic practice. No use, distribution or reproduction is permitted which does not comply with these terms. 